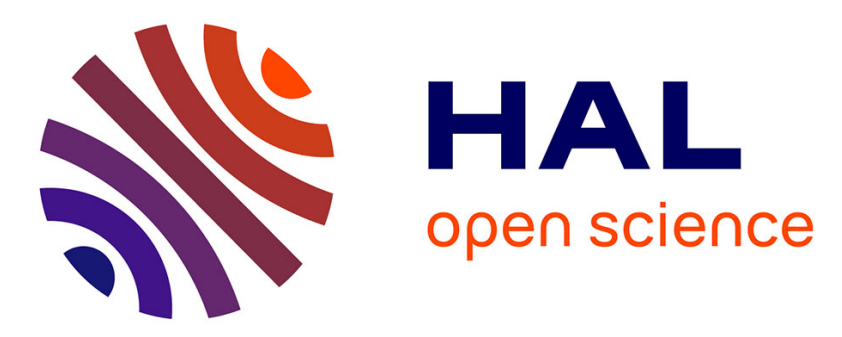

\title{
Pallidal stimulation in Parkinson's patients with contraindications to subthalamic target: A 3 years follow-up
}

Julien Bonenfant, Sophie Drapier, Jean François Houvenaghel, Florian Naudet, Claire Haegelen, Paul Sauleau, Marc Vérin

\section{To cite this version:}

Julien Bonenfant, Sophie Drapier, Jean François Houvenaghel, Florian Naudet, Claire Haegelen, et al.. Pallidal stimulation in Parkinson's patients with contraindications to subthalamic target: A 3 years follow-up. Parkinsonism \& Related Disorders, 2017, 34, pp.20-25. 10.1016/j.parkreldis.2016.10.007 . hal-01386883

\section{HAL Id: hal-01386883 https://hal.science/hal-01386883}

Submitted on 3 Feb 2017

HAL is a multi-disciplinary open access archive for the deposit and dissemination of scientific research documents, whether they are published or not. The documents may come from teaching and research institutions in France or abroad, or from public or private research centers.
L'archive ouverte pluridisciplinaire HAL, est destinée au dépôt et à la diffusion de documents scientifiques de niveau recherche, publiés ou non, émanant des établissements d'enseignement et de recherche français ou étrangers, des laboratoires publics ou privés. 


\title{
Pallidal stimulation in Parkinson's patients with contraindications to subthalamic target: a 3 years follow-up
}

\author{
Julien BONENFANT, MD ${ }^{1}$ \\ Sophie DRAPIER, MD ${ }^{1,2}$ \\ Jean François HOUVENAGHEL, PhD, ${ }^{1,2}$ \\ Florian NAUDET, MD, $\mathrm{PhD}^{3}$ \\ Claire HAEGELEN, MD, $\mathrm{PhD}^{4,5}$ \\ Paul SAULEAU, MD, PhD ${ }^{2,7}$ \\ Marc VERIN, MD, PhD ${ }^{1,2}$ \\ 1 Department of Neurology, University Hospital of Rennes, 35043 Rennes, France \\ 2“Behavior and Basal Ganglia" research unit (EA 4712), University of Rennes 1, 35043 Rennes, \\ France \\ ${ }^{3}$ Clinical Investigation Center (INSERM 0203), Department of Pharmacology, Rennes University \\ Hospital, 35033 Rennes, France \\ ${ }^{4}$ Department of Neurosurgery Rennes University Hospital, 35033 Rennes, France \\ 5“MediCIS" laboratory (UMR 1099 LTSI), INSERM/University of Rennes, Rennes, France \\ ${ }^{7}$ Department of Neurophysiology, Rennes University Hospital, F-35033 Rennes, France
}

Corresponding author: Dr J. Bonenfant, Service de Neurologie, Centre Hospitalier Universitaire de Rennes, 35033 Rennes, France. E-mail : julien.bonenfant@chu-rennes.fr

Word count: 2231

Running title: 3 years GPi-DBS in Parkinson's disease

Key words: Parkinson's disease; deep brain stimulation; Pallidal stimulation; neuropsychological outcome; axial motor symptoms

Financial Disclosure/Conflict of Interest: No financial disclosure or conflict of Interest

This research did not receive any specific grant from funding agencies in the public, commercial, or not-for-profit sectors. 


\section{Abstract:}

Introduction: Over a 3-year period, we monitored the efficacy and safety of deep-brain stimulation of the globus pallidus pars interna in patients with advanced Parkinson's disease whose cognitive, psychiatric impairment and/or dopa-resistant axial motor signs made them ineligible for surgery targeting the subthalamic nucleus.

Methods: A total of 25 patients were assessed before surgery, 1 year and 3 years after surgery, on the UPDRS and a neuropsychological battery.

Results: We noted a significant improvement of $65.9 \%$ in the Clinical global self-perceived Improvement by Visual Analog Scale and an improvement of $20.6 \%$ in the total UPDRS-III motor score at 3 years in the off-dopa condition compared to before surgery. There was an improvement in the treatment's motor complications, as measured by the UPDRS-IV, with a particularly marked reduction of $50 \%$ in the Dyskinesia subscore. Cognitive performances remained stable at 1 year but had fallen by the third year. We interpreted this deterioration as due to disease progression.

Conclusion: Bilateral pallidal stimulation in patients with contraindications to subthalamic surgery therefore seems to be effective over the long term in treating motor symptoms, especially dyskinesias, with good neuropsychological safety.

\section{INTRODUCTION}

Functional neurosurgery for deep-brain stimulation (DBS) has been validated as an effective treatment of choice in patients with Parkinson's disease (PD) refractory to medical treatment.[1,4] The optimal target is still debated, some studies seems to show a superiority of the subthalamic nucleus (STN) over the globus pallidus pars interna (GPi),[5,7] but some don't.[8,10] However, STN DBS has been shown to carry a risk of disabling side effects, including cognitive decline,[11,12] limbic effect [13] and the worsening of dopa-resistant axial motor signs.[14] In the light of these side effects, we can now identify patients who should not undergo subthalamic surgery.[15] As GPi DBS appears to entail less cognitive deterioration and fewer axial signs, [16] several centers have started offering this treatment to patients contraindicated to STN DBS. Its efficacy and safety have already been studied at 6 months post-surgery [17] in one such group of patients, with a motor benefit, no worsening of axial symptoms and no cognitive impairment. In the present study, we monitored its efficacy and safety in patients receiving bilateral pallidal stimulation over a 3-year period. All these patients had advanced PD refractory to all the usual medical treatments, with contraindications to STN DBS.

\section{MATERIAL AND METHODS}

\section{Patients}


During the 2004-2011 periods, 87 patients were selected for DBS surgery with idiopathic PD at Rennes University Hospital. The decision to operate had been taken because all the usual medical treatments had failed to adequately control the symptoms of the disease, and patients had a levodopa (L-dopa) responsiveness of $\geq 50 \%$, as measured by the motor score of the United Parkinson's Disease Rating Scale (UPDRS).

Along those 87 patients, 2 refused the surgical procedure, 60 underwent STN-DBS and we studied the 25 patients who had undergone GPi DBS surgery, corresponding to the patients who had been rejected for STN surgery.

The contraindication for STN surgery was, general cognitive impairment (Mattis Dementia Rating Scale (MDRS) score < 130),[18] impaired executive functions (impaired scores at almost three tests among the battery of tests assessing executive functions, according to the normal values expected in regard of age and educational level) before surgery and/or dopa-resistant axial signs (preoperative UPDRS III axial score $\geq 3$ in the on-dopa condition). $[19,20]$ Table 1 set out the patients' characteristics immediately prior to surgery.

At 3 years, one patient could not be assessed at all, owing to an advanced dementia syndrome, and two patients did not undergo the neuropsychological tests due to cognitive impairment.

\section{Surgical procedure}

Quadripolar DBS electrodes (Medtronic, Minneapolis, MN) were implanted bilaterally in the posteroventral part of the GPi under general anesthesia in a single operating session. All dopaminergic medication had been withdrawn the day before, and patients were briefly woken during the procedure to test the clinical effect of stimulation on rigidity. The ventral contact was kept above the optical tract, as evidenced by the induction of visual flashes by stimulation. There was no Intraoperative microelectrode recording during the procedure.

The pulse generators (Soletra, Medtronic) were implanted 2-3 days later. The exact location of the two selected electrode contacts (one on the left and one on the right) was determined using stereotactic coordinates derived from a 3D CT scan performed a few days after surgery. The stimulation parameters were set and adjusted during appointments with the consultant and regular follow-up hospitalizations, based solely on clinical efficacy criteria.

\section{Assessments}

The patients were assessed before surgery (baseline), 1 year (M12) and 3 years (Y3) after surgery. The clinical assessment included the UPDRS parts I (mental, behavior and mood), II (activities of daily living), III (motor performance) and IV (complications of therapy in the past week). The off-dopa condition of the UPDRS-III was at least 8 hours after all medication had been halted, and the on-dopa condition was performed after patients had received a dose of L-dopa in the form of dispersible levodopa-benserazide, corresponding to their usual morning dose of dopaminergic medication plus 50 mg.

We defined 4 subscores from the UPDRS III, the "axial score" (out of 20) defined as the sum of items 18 (speech), 27 (rising from chair), 28 (posture), 29 (gait), and 30 (posture stability); the "speech 
score" (out of 4) defined as item 18 (speech); the "akinesia score" (out of 32) defined as the sum of items 23 (finger taps), 24 (hand movements), 25 (rapid alternating movements of hands), and 26 (leg agility); the "Tremor score" (out of 28) defined as the sum of items 20 (tremor at rest) and 21 (action or postural tremor of hands).

We also defined a "dyskinesia score" (out of 13) corresponding to the sum of items 32, 33, 34 and 35 and a "motor fluctuations score" (out of 7) corresponding to the sum of items $36,37,38$ and 39 of the UPDRS IV.

Patients underwent a neuropsychological battery, comprising the MDRS, Trail Making Test (TMT), Nelson's modified Wisconsin Card Sorting Test (WCST), Stroop test, and semantic and phonemic verbal fluency test.

The Hoehn and Yahr (H\&Y) and Schwab and England (S\&E) scores were also collected, along with two self-rated quality of life (QoL) scores (SF-36 and PDQ-39).

Daily dopaminergic treatment was defined as the L-dopa equivalent dose (LED), calculated using method of Deuschl et al. [21]

A global self-perceived Improvement was measured with a single-item Visual Analog Scale (VAS-I) ranging from $0 \%$ (no change) to $100 \%$ (best improvement). [22] The question was worded: "compared to the time before your operation, how would you judge your global improvement at the moment?"

\section{Statistical analysis}

We compared the different variables using the Wilcoxon signed-rank test, with the significance threshold set at $p=0.05$. All the data are shown as means \pm standard deviation $(S D)$. Analyses were performed using $\mathrm{R}$ [R Development Core Team: R: A Language and Environment for Statistical Computing. Vienna, Austria: R Foundation for Statistical Computing; 2009.].

\section{RESULTS}

\section{Motor results}

The VAS-I score was $64 \pm 23.9 \%$ at M12, and remained unchanged at Y3 $(65.9 \pm 15.6 \% ; p=1)$.

When the patients were stimulated (on stim), but without their dopaminergic medication (off dopa), there was a significant $19.8 \%$ improvement in the total motor score of the UPDRS-III at M12 ( $p=$ $0.04)$, which was maintained at $Y 3$, with an improvement of $20.6 \%$ compared with baseline $(p=0.04)$ (Table 2). An improvement in the Tremor subscore tended toward significance. We did not find any change in the Axial, Akinesia or Speech subscores, which remained stable at M12 and Y3. The UPDRS-II, the H\&Y and the S\&E scores measuring activities of daily living also remained stable at $\mathrm{M} 12$ and $\mathrm{Y} 3$.

In the on-stim/on-dopa conditions, patients' total motor score was stable at M12 $(p=0.13)$ and remained so at Y3 $(p=0.27)$ (Table 3$)$. The Akinesia, Tremor and Axial subscores were also stable, with no significant deterioration at either M12 or Y3. There was, however, a significant worsening of the Speech subscore by M12 $(p=0.002)$. This was still present at $Y 3$, but there had been no further 
decline. There was a significant deterioration in the UPDRS-II score at Y3 compared with baseline $(p=0.002)$. The S\&E and H\&Y scores remained unchanged.

\section{Motor complications of medical therapy}

There was an improvement of $28.5 \%(p=0.009)$ of the UPDRS-IV at M12 and $33 \%$ at $Y 3(p=0.02)$ compared with baseline (Table 3), especially for the Dyskinesias subscore, which improved by $50 \%$ at M12 $(p=0.009)$ and $52 \%$ at Y3 $(p=0.007)$ (Table 3). No significant improvement in the Motor Fluctuations subscore was found.

\section{Cognitive and neuropsychological results}

At M12, all the cognitive and psychiatric abilities, as assessed with the UPDRS-I and the neuropsychological tests, did not change. By contrast, at $Y 3$, we found significant deteriorations in the MDRS score $(p=0.049)$, the Stroop color-word $(p=0.01)$ and interference $(p=0.01)$ scores, and the TMT B-A $(p=0.01)$ score (Table 4$)$. There was also a trend toward a worsening of the UPDRS-I score. Semantic and phonemic verbal fluency remained stable, as did WCST scores.

\section{Quality-of-life scales}

The SF-36 QoL score showed a trend toward deterioration between baseline and Y3 (48.8 \pm 18 vs. $41.1 \pm 14.7 ; p=0.06$ ), whereas the PDQ-39 scale remained stable over this period ( $38.21 \pm 9$ vs. 39.5 $\pm 11.8 ; p=0.83$ ).

\section{Safety}

One patient's electrode malfunctioned by $\mathrm{Y} 3$, following a fall with minor concussion, and one patient had to have an electrode removed at 2 years, after developing an infection (which responded favorably to treatment) without replacement. None of the patients died during follow-up.

\section{Stimulation parameters and dopaminergic medication}

The stimulation parameters (mean $\pm S D$ ) at $Y 3$ for the 25 patients were $2.96 \pm 0.36 \mathrm{~V}$, with a pulse width of $84.1 \pm 21.6 \mu \mathrm{s}$ and a frequency of $133.5 \pm 14.9 \mathrm{~Hz}$. At $Y 3$, nine patients were stimulated using two contacts on each side, two patients were unilaterally stimulated via two contacts, while 14 patients were bilaterally stimulated via one contact on each side. None of the patients needed to have their neurostimulator changed during the 3 years of the study. The stimulation did not bring about any reduction in the LED, which was $1263 \pm 513 \mathrm{mg}$ at baseline, $1431 \pm 438 \mathrm{mg}$ at M12, and $1375 \pm 617$ $\mathrm{mg}$ at $\mathrm{Y} 3$.

\section{DISCUSSION}

For patients with advanced Parkinson's disease refractory to medical treatment, the existence of doparesistant axial motor signs or cognitive impairment, leads to contraindication for surgical option. We 
believe that these contraindications are specific to STN DBS and cannot be applied to GPI DBS, because pallidal surgery appears to entail less cognitive deterioration and fewer axial signs.[16,17] Our results shows a motor benefits in the off-dopa condition that is still present 3 years after surgery, corresponding to the effect of the stimulation without any medication. In the on-dopa condition, we did not find any modification in the total motor score and no worsening of the Motor Fluctuations subscore, despite the expected disease progression, the motor benefit could be interpreted as low, but cannot be compared to the benefits in other studies on GPI DBS, because our patients due to the advanced PD and dopa resistant symptoms are systematically contraindicated for surgery in those studies.

We also find a major antidyskinetic effect, with a reduction at $Y 3$ of more than $50 \%$ in the baseline Dyskinesias score, even though there was no postoperative reduction in dopaminergic medication. This result confirms the specific antidyskinetic effect of the pallidal target, an effect that was maintained over time. The major reduction on dyskinesias is constantly found in the published data on GPI DBS, confirming the interest of this target on dyskinesias.[23,24]

We confirm the tolerance of this target with no worsening of dopa-resistant axial motor signs present prior to surgery, even though the patients selected were an at-risk population. This suggest that the stimulation had no adverse effect on axial signs at M12 and $\mathrm{Y} 3$, in contrast to previous reports.[25] Although there have been suggestions that GPi DBS leads to a worsening of akinetic symptoms, we did not observe any deterioration in the Akinesia subscore during the 3-year follow-up period. We did not evaluated adverse effects such as fatigue, apathy, mobility/falls and ICD and it will be useful to evaluate them with specific scales in further studies.

Dysarthria however was the only symptom that significantly worsened, with an early decline in the first year, but none thereafter. This early deterioration suggest that it was an effect of the surgery, rather than of disease progression. We therefore believe it is important to make this particular risk known and take it into account when discussing the risks and benefits with patients who are potentially suitable for GPi surgery.

On cognitive assessments, at M12, the neuropsychological parameters remained unchanged, without early worsening, attributed to the stimulation, such as has been reported in some studies of STN DBS.[26,29] At Y3, however, some scores underwent a belated decline. In our patients, with advanced PD with cognitive impairment prior to surgery, we believe that this deterioration reflect the effect of disease progression, rather than a harmful effect of the surgery, because of the absence of early deterioration, such as suggested in other studies reporting the long-term follow-up of DBS.[30]

There was a major self-estimated global clinical improvement of $65 \%$ still present at 3 years after the surgery. By contrast, there was no improvement in QoL and even a worsening of the UPDRS II at 3 years. We think that this discrepancy can be explained by the scales we used to measure this variable, as they are not particularly sensitive to change. We could also incriminate the cognitive impairment, responsible of a worsening of quality of life independently of the motor benefits, but this point on the effectiveness of the GPi DBS should be assessed in further studies.

Our study had however some obvious limitations as the size of the population, the observational design and the absence of control group. A comparison to a nonsurgical control population over the 
same period of time would help to assess the long term effectiveness and cognitive tolerance of the stimulation.

\section{CONCLUSION}

GPi DBS in patients deemed ineligible for STN stimulation, owing to cognitive impairment or doparesistant axial signs, effectively reduces motor symptoms, and the benefits last at least 3 years. Pallidal stimulation also considerably lessens treatment-induced motor complications, especially dyskinesias. It did not bring about any increase in akinesia, and had no adverse impact on axial signs and neuropsychological parameters. By contrast, there was a significant deterioration in speech, which will need to be taken into account when deciding on the most appropriate course of action. These results suggest that GPi DBS is a viable treatment for advanced idiopathic PD in patients ineligible for STN DBS, especially if they have acute dyskinetic complications, but those results are far from being definitive and should be assessed in further prospective studies.

Acknowledgment: We like to thanks Mr Pierre Vérin for collecting the data and Mrs Elisabeth PortierWiles for preparing the manuscript.

Author Roles:

Julien Bonenfant was involved in the conception,

organization, and execution of research project;

design, execution, and review and critique of statistical analysis;

writing of the first draft of manuscript.

Sophie Drapier was involved in the execution of research project; review and critique of statistical analysis; review and critique of manuscript.

Jean-François Houvenaghel was involved in the neuropsychological assessments, review and critique of manuscript.

Florian Naudet was involved in the design and execution of statistical analysis; review and critique of manuscript.

Claire Haegelen was involved in the review and critique of manuscript.

Paul Sauleau was involved in the review and critique of manuscript.

Marc Vérin was involved in the conception and organization of research project; design and review and critique of statistical analysis; review and critique of manuscript.

Financial Disclosures: None. 


\section{REFERENCES}

1. Limousin P, Krack P, Pollak P, Benazzouz A, Ardouin C, Hoffmann D, Benabid AL. Electrical stimulation of the subthalamic nucleus in advanced Parkinson's disease. N Engl J Med 1998;339:1105-1111.

2. Kumar R, Lozano AM, Kim YJ, Hutchison WD, Sime E, Halket E, Lang AE. Double-blind evaluation of subthalamic nucleus deep brain stimulation in advanced Parkinson's disease. Neurology 1998;51:850-855.

3. Durif F, Lemaire JJ, Debilly B, Dordain G. Long-term follow-up of globus pallidus chronic stimulation in advanced Parkinson's disease. Mov Disord 2002;4:803-807.

4. The Deep-Brain Stimulation for Parkinson's Disease Study Group. Deep-brain stimulation of the subthalamic nucleus or the pars interna of the globus pallidus in Parkinson's disease. N Engl J Med 2001;27:956-963.

5. Krack P, Pollak P, Limousin P, Hoffmann D, Xie J, Benazzouz A, Bebabid AL. Subthalamic nucleus or internal pallidal stimulation in young onset Parkinson's disease. Brain 1998;121:451-457.

6. Krause M, Fogel W, Heck A, Hacke W, Bonsanto M, Trenkwalder C, Tronnier V. Deep brain stimulation for the treatment of Parkinson's disease: subthalamic nucleus versus globus pallidus internus. J Neurol Neurosurg Psychiatry 2001;70:464-470.

7. Odekerken VJ, Boel JA, Schmand BA, de Haan RJ, Figee M, van den Munckhof P, Schuurman PR, de Bie RM, NSTAPS study group. GPi vs STN deep brain stimulation for Parkinson disease: Three-year follow up. Neurology 2016;86:75561.

8. Follett KA, Weaver FM, Stern M, Hur K, Harris CL, Luo P, Marks WJ Jr, Rothlind J, Sagher O, Moy C, Pahwa R, Burchiel K, Hogarth P, Lai EC, Duda JE, Holloway K, Samii A, Horn S, Bronstein JM, Stoner G, Starr PA, Simpson R, Baltuch G, De Salles A, Huang GD, Reda DJ; CSP 468 Study Group. Pallidal versus subthalamic deep-brain stimulation for Parkinson's disease. N Engl J Med 2010;362:2077-2091.

9. Liu Y, Li W, Tan C, Liu X, Wang X, Gui Y, Qin L, Deng F, Hu C, Chen L. Meta-analysis comparing deep brain stimulation of the globus pallidus and subthalamic nucleus to treat advanced Parkinson disease. J Neurosurg. 2014;121:70918.

10. Katayama Y, Kasai M, Oshima H, Fukaya C, Yamamoto T, Mizutani T. Double blinded evaluation of the effects of pallidal and subthalamic nucleus stimulation on daytime activity in advanced Parkinson's disease. Parkinsonism Relat Disord 2000;7:35-40.

11. Massano J, Garrett C. Deep brain stimulation and cognitive decline in Parkinson's disease: a clinical review. Front Neurol 2012; 3:66.

12. Parson T, Rogers S, Braaten A, Woods SP, Troster A. Cognitive sequelae of subthalamic nucleus deep brain stimulation in Parkinson's disease: a meta-analysis. Lancet Neurol 2006; 5:578-588.

13. Drapier D, Drapier S, Sauleau P, Haegelen C, Raoul S, Biseul I, Peron J, Lallement F, Rivier I, Reymann JM, Edan G, Verin M, Millet B. Does subthalamic nucleus stimulation induce apathy in Parkinson's disease? J Neurol 2006;253:10831091. 
14. Allert N, Volkmann J, Dotse S, Hefter H, Sturm V, Freund HJ. Effects of bilateral pallidal or subthalamic stimulation on gait in advanced Parkinson's disease. Mov Disord 2001;16:1076-1085.

15. Welter ML, Houeto JL, Tezenas du Montcel S, Mesnage V, Bonnet AM, Pillon B, Arnulf I, Pidoux B, Dormont D, Cornu $\mathrm{P}$, Agid Y. Clinical predictive factors of subthalamic stimulation in Parkinson's disease. Brain 2002;125:575-583.

16. Rodriguez-Oroz MC, Obeso JA, Lang AE, Houeto JL, Pollak P, Rehncrona S, Kulisevsky J, Albanese A,Volkmann J, Hariz MI, Quinn NP, Speelman JD, Guridi J, Zamarbide I, Gironell A, Molet J, Pascual-Sedano B, Pidoux B, Bonnet AM, Agid Y, Xie J, Benabid AL, Lozano AM, Saint-Cyr J, Romito L,Contarino MF, Scerrati M, Fraix V, Van Blercom N. Bilateral deep brain stimulation in Parkinson's disease: a multicentre study with 4 years follow-up. Brain 2005;128:2240-2249.

17. Rouaud T, Dondaine T, Drapier S, Haegelen C, Lallement F, Péron J, Raoul S, Sauleau P, Vérin M. Pallidal stimulation in advanced Parkinson's patients with contraindications for subthalamic stimulation. Mov Disord 2010;25:1839-1846.

18. Silberstein P, Bittar RG, Boyle R, Cook R, Coyne T, O'Sullivan D, Pell M, Peppard R, Rodrigues J,Silburn P, Stell R, Watson P; Australian DBS Referral Guidelines Working Group. Deep brain stimulation for Parkinson's disease: Australian referral guidelines. J Clin Neurosci 2009;16:1001-1008.

19. Jarraya B, Bonnet AM, Duyckaerts C, Houeto JL, Cornu P, Hauw JJ, Agid Y. Parkinson's disease, subthalamic stimulation, and selection of candidates: A a pathological study. Mov Disord 2003;18:1517-1520.

20. Charles PD, Van Blercom N, Krack P, Lee SL, Xie J, Besson G, Benabid AL, Pollak P. Predictors of effective bilateral subthalamic nucleus stimulation for PD. Neurology 2002;59:932-934.

21. Deuschl G, Schade-Brittinger C, Krack P, Volkmann J, Schäfer H, Bötzel K, Daniels C, Deutschländer A,Dillmann U, Eisner W, Gruber D, Hamel W, Herzog J, Hilker R, Klebe S, Kloss M, Koy J, Krause M,Kupsch A, Lorenz D, Lorenzl S, Mehdorn HM, Moringlane JR, Oertel W, Pinsker MO, Reichmann H, Reuss A, Schneider GH, Schnitzler A, Steude U, Sturm V, Timmermann L, Tronnier V, Trottenberg T,Wojtecki L, Wolf E, Poewe W, Voges J; German Parkinson Study Group, Neurostimulation Section. N Engl J Med 2006;355:896-908.

22. de Boer AG, van Lanschot JJ, Stalmeier PF, van Sandick JW, Hulscher JB, de Haes JC. Is a single-item visual analog scale as valid, reliable and responsive as multi-item sacles in measuring quality of life? Qual Life Res 2004;13:311-320.

23. Fasano A, Daniele A, Albanese A: Treatment of motor and non-motor features of Parkinson's disease with deep brain stimulation. Lancet Neurol. 2012;11:429-442

24. Oyama G, Foote KD, Jacobson CE 4th, Velez-Lago F, Go C, Limotai N, Zeilman PR, Romrell J, Wu SS, Neal D, Okun MS: GPi and STN deep brain stimulation can suppress dyskinesia in Parkinson's disease. Parkinsonism Relat Disord 2012;18:814-818.

25. Deuschl G, Herzog J, Kleiner-Fisman G, Kubu C, Lozano AM, Lyons KE, Rodriguez-Oroz MC, Tamma F, Tröster AI, Vitek JL, Volkmann J, Voon V. Deep brain stimulation: Postoperative issues. Mov Disord 2006;21:S219-237.

26. Saint-Cyr JA, Trépanier LL, Kumar R, Lozano AM, Lang AE. Neuropsychological consequences of chronic bilateral stimulation of the subthalamic nucleus in Parkinson's disease. Brain 2000; 123:2091-2108.

27. Dujardin K, Defebvre L, Krystkowiak P, Blond S, Destee A. Influence of chronic bilateral stimulation of the subthalamic nucleus on cognitive function in Parkinson's disease. J Neurol 2001;248:603-611.

28. Jahanshahi M, Ardouin CM, Brown RG, Rothwell JC, Obeso J, Albanese A, Rodriguez-Oroz MC, Moro E, Benabid AL, Pollak P. The impact of deep brain stimulation on executive function in Parkinson's disease. Brain 2000;123:1142-1154. 
29. Hershey T, Revilla FJ, Wernle A, Gibson PS, Dowling JL, Perlmutter JS. Stimulation of STN impairs aspects of cognitive control in PD. Neurology 2004;62:1110-1114.

30. Krack P, Batir A, Van Blercom N, Chabardes S, Fraix V, Ardouin C, Koudsie A, Limousin PD,Benazzouz A, LeBas JF, Benabid AL, Pollak P. Five-year follow-up of bilateral stimulation of the subthalamic nucleus in advanced Parkinson's disease. N Engl J Med 2003;349:1925-1934. 
Table 1.

Characteristics of the 25 patients prior to surgery

Male

Mean age at surgery (years)

Mean disease duration at surgery (years)

Mean levodopa dose (mg/d)
Value

$13(52 \%)$

$60 \pm 7.5$

$12.5 \pm 6.25$

$1263 \pm 513$ 
Table 2

\begin{tabular}{|c|c|c|c|c|c|c|}
\hline \multicolumn{7}{|c|}{ Effects of stimulation in the off-dopa/on-stim condition } \\
\hline & Baseline & M12 & Y3 & & & \\
\hline & Off-dopa & Off-dopa/on-stim & Off-dopa/on-stim & \multicolumn{3}{|c|}{$P$-value } \\
\hline & $n=25$ & $\mathrm{n}=25$ & $n=24$ & M12vs.B & Y3vs.B & Y3vs.M12 \\
\hline UPDRS-II (/52) & $20.7 \pm 7.8$ & $20.8 \pm 8.1$ & $20.3 \pm 10.2$ & 0.88 & 0.69 & 0.8 \\
\hline UPDRS-III (/108) & $37.3 \pm 15.3$ & $29.9 \pm 11.2$ & $29.6 \pm 18.3$ & $0.04^{*}$ & $0.04^{*}$ & 0.42 \\
\hline Akinesia score (/32) & $14.9 \pm 6.9$ & $12.4 \pm 6.6$ & $14.7 \pm 8.7$ & 0.15 & 0.69 & 0.63 \\
\hline Tremor score (/28) & $4.7 \pm 5.3$ & $3.2 \pm 3.7$ & $2.5 \pm 2.9$ & 0.16 & 0.09 & 0.26 \\
\hline Axial motor score (/20) & $8.1 \pm 3.6$ & $6.6 \pm 3.3$ & $7.3 \pm 4.9$ & 0.11 & 0.17 & 0.72 \\
\hline Speech score (/4) & $1.5 \pm 0.9$ & $1.7 \pm 0.9$ & $1.9 \pm 1.1$ & 0.52 & 0.14 & 0.26 \\
\hline $\mathrm{H} \& Y(/ 5)$ & $3.2 \pm 1.1$ & $3.2 \pm 1.2$ & $3.1 \pm 1$ & 0.69 & 0.81 & 0.75 \\
\hline S\&E (/100\%) & $54.4 \pm 23.6$ & $62.2 \pm 18.3$ & $58.3 \pm 1$ & 0.21 & 0.81 & 0.42 \\
\hline
\end{tabular}

All values are shown as means \pm standard deviation. UPDRS $=$ United Parkinson's Disease Rating Scale. H\&Y $=$ Hoehn and Yahr. S\&E = Schwab and England. A reduction in these scores (apart from H\&Y and S\&E) represented a functional improvement. Patients' status was assessed off dopaminergic medication (off dopa), but with stimulation (on stim) at 1 year and 3 years. Comparisons were made between baseline and 1 year (M12vs.B), baseline and 3 years (Y3vs.B), and 1 year and 3 years (A3vs.M12). Statistically significant improvement is denoted by *. 
Table 3

\begin{tabular}{|c|c|c|c|c|c|c|}
\hline \multicolumn{7}{|c|}{ Effects of stimulation in the on-dopa/on-stim condition } \\
\hline & Baseline & M12 & Y3 & & & \\
\hline & On-dopa & On-dopa/on-stim & On-dopa/on-stim & \multicolumn{3}{|c|}{$p$-value } \\
\hline & $n=25$ & $n=25$ & $n=24$ & M12vs.B & Y3vs.B & Y3vs.M12 \\
\hline UPDRS-II (/52) & $8.1 \pm 6$ & $10.8 \pm 6.8$ & $13.2 \pm 7.5$ & 0.15 & $0.002 \dagger$ & $0.01 \dagger$ \\
\hline UPDRS-III (/108) & $11.9 \pm 5.4$ & $14.3 \pm 6.6$ & $15 \pm 10.1$ & 0.13 & 0.27 & 1 \\
\hline Akinesia score (/32) & $4.9 \pm 2.5$ & $5.9 \pm 4.1$ & $7.3 \pm 6.9$ & 0.41 & 0.10 & 0.77 \\
\hline Tremor score (/28) & $0.8 \pm 1.4$ & $0.7 \pm 0.8$ & $0.7 \pm 0.9$ & 0.96 & 0.90 & 1 \\
\hline Axial score (/20) & $3.2 \pm 2.3$ & $4 \pm 2.5$ & $4.6 \pm 3.5$ & 0.27 & 0.11 & 0.74 \\
\hline Speech score (/4) & $0.9 \pm 0.7$ & $1.6 \pm 1$ & $1.4 \pm 1.2$ & $0.002 \dagger$ & 0.08 & 0.5 \\
\hline H\&Y (/5) & $1.9 \pm 1$ & $1.8 \pm 0.8$ & $2.3 \pm 1.1$ & 0.75 & 0.13 & 0.09 \\
\hline S\&E (/100\%) & $83.2 \pm 14.3$ & $84.8 \pm 15.9$ & $77.9 \pm 16.7$ & 0.68 & 0.18 & $0.02 \dagger$ \\
\hline UPDRS-IV (/24) & $8.8 \pm 3.7$ & $6.3 \pm 3.3$ & $5.9 \pm 2.9$ & $0.009^{*}$ & $0.02^{*}$ & 0.6 \\
\hline Dyskinesia score (/13) & $4.6 \pm 2.9$ & $2.3 \pm 2.7$ & $2.2 \pm 2.1$ & $0.009^{*}$ & $0.007^{*}$ & 0.78 \\
\hline Motor Fluctuations score (/7) & $3.3 \pm 1.5$ & $2.9 \pm 1.6$ & $2.9 \pm 1.3$ & 0.32 & 0.55 & 0.98 \\
\hline
\end{tabular}

All values are shown as means \pm standard deviation. UPDRS $=$ United Parkinson's Disease Rating Scale. H\&Y $=$ Hoehn and Yahr. S\&E = Schwab and England. A reduction in these scores (apart from H\&Y and S\&E) represented a functional improvement. Patients' status was assessed with dopaminergic medication (on dopa), and with electrical stimulation (on stim) at 1 year and 3 years. The comparisons were made between baseline and 1 year (M12vs.B), baseline and 3 years (Y3vs.B), and 1 year and 3 years (Y3vs.M12). Statistically significant improvement is denoted by *. Statistically significant worsening is denoted by t. 


\section{ACCEPTED MANUSCRIPT}

Table 4

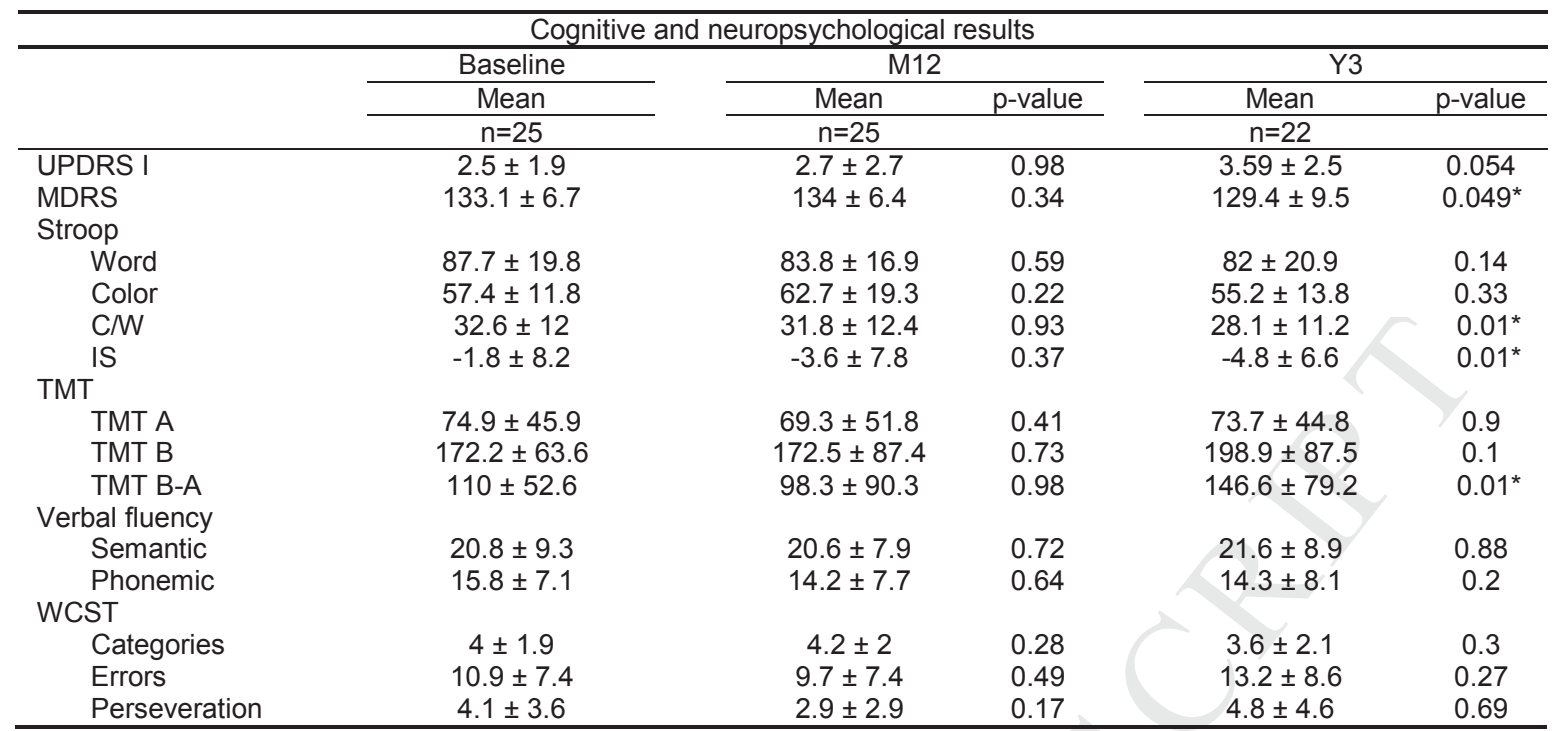

All values are shown as means \pm standard deviation. UPDRS = United Parkinson's Disease Rating Scale; MDRS = Mattis Dementia Rating Scale; C/W = color word; IS = interference score; TMT = Trail Making Test; WCST = Wisconsin Card Sorting Test; The situations at 1 year (M12) and 3 years (A3) are compared with the preoperative situation (baseline). Statistically significant improvement is denoted by * 
Highlights

- Efficacy at 3 years of GPi DBS in patients deemed ineligible for STN DBS.

No adverse impact of GPi DBS on axial signs and neuropsychological parameters. 